\title{
The Integrated Territorial Investment (ITI) of the Mar Menor as a model for the future in the comprehensive management of enclosed coastal seas
}

\author{
Salvador Garcia-Ayllon \\ General Directorate of Transports, Coasts and Ports of the Region of Murcia, Spain
}

\section{A R T I C L E I N F O}

\section{Keywords:}

ITI Mar Menor

Integrated territorial investment

Enclosed coastal sea management

Integrated coastal lagoon strategy

\begin{abstract}
A B S T R A C T
The Mar Menor, a coastal lagoon in south-eastern Spain of high environmental value and protected by the Natura 2000 network, suffered an intense phenomenon of eutrophication in 2015. This phenomenon generated a change of colour and important increase in the turbidity of its waters, which caused the loss of $85 \%$ of its marine vegetal cover in 2016 and great social alarm. The various regulations and tools of environmental protection that exist have not worked properly to avoid the anthropization of this enclosed coastal sea, which is subjected to a varied catalogue of human activities that encompass mass tourism, agriculture, mining, fishing or the important presence of ports and infrastructures, among others. In this context, the Integrated Territorial Investment (ITI) of the Mar Menor is put in place as an innovative model of integrated strategy for coastal zone management (ICZM) to overcome the shortcomings of previous management systems.

This paper analyzes the process to implement this new model of comprehensive governance in the Mar Menor. The work is based on the use of participatory mechanisms for collaboration with stakeholders, in order to reach an integrated diagnosis and propose comprehensive solutions that involve all actors related to the current situation. The model performs the socio-ecological system of the Mar Menor (SESMM) that physically surpasses the geographic surface of the lagoon managed by traditional environmental tools. In this way, four different areas of influence of the lagoon are diagnosed and integrated into a sectoral action plan with the help of GIS tools in a process called "GIS participatory mapping". The analysis carried out shows how the origin of the lagoon's main problems often lie many kilometres away from the lagoon itself and thus the situation needs to be addressed from a multidisciplinary perspective to find effective solutions. The results will help us set up a new management framework to achieve the recovery of the lagoon and sustainable future cohabitation among the existing activities. The approach taken (which can be easily exported to other coastal areas with complex environmental problems associated with diffuse anthropization) shows the importance of proposing analysis methodologies that are capable of involving all stakeholders to achieve sustainable solutions over time.
\end{abstract}

\section{Introduction}

Integrated strategies for coastal zone management (hereinafter ICZM) are currently a scientific area with an important bibliography background but also with a growing research interest (McFadden and Schernewski, 2014; Newton et al., 2014). Within this field, coastal lagoons are usually complex transitional waters highly subscribed to management research. This is because of the important natural values that are usually present in these territories in cohabitation with human activities (good references of individual studies can be found for example in Bellio and Kingsford, 2013; O'Neill et al., 2015 or Fiandrino et al., 2017 and some theoretical general approaches in Casini et al., 2015; Conde et al., 2015 or Tavares et al., 2015).

In these singular areas, eutrophication problems associated to human activities are not an uncommon issue. They can be quite frequently found related mainly to sewage discharges (see interesting cases in French lagoons in Leruste et al., 2016), intensive agriculture (e.g. classical US very damaged Salton Sea lagoon, in Boyle, 1996 or more recent growing problems in five cases in Uruguay, RodriguezGallego et al., 2017), industry (Sujitha et al., 2017) or even climate change (Domingues et al., 2017). In this field, those that carry a complex context not offering a clear direct cause (Mitchell et al., 2017) or those that are submitted to changing boundary conditions (Thorne et al., 2017) are especially interesting for management research. Recent interesting proposals for lagoon management and restoration can be found in current scientific literature (e.g. De Wit et al., 2017; Povilanskas et al., 2014 or Yáñez-Arancibia et al., 2014) introducing attractive topical issues such as the need for government involvement (Zaldívar-Jiménez et al., 2017) or stakeholders' willingness to pay (Tuan et al., 2014). Moreover, nowadays we can find different

E-mail address: salgarve@ciccp.es. 
approaches regarding the method to carry out ICZM, from an Ecosystem services framework (MEA, TEEB, CICES) currently used for mapping and assessment in EU Biodiversity Strategy to 2020 (Turner and Daily, 2008 ) to the multi-level nested framework for socioecological systems (Ostrom, 2009).

In this context, the recent problems in the Mar Menor provide a very interesting case in the field of research in the management of coastal areas subjected to processes of diffuse anthropization. The Mar Menor is a coastal salt-water lagoon (between 135 and $170 \mathrm{~km}^{2}$, mean depth $3.6 \mathrm{~m}$, with maximum $6 \mathrm{~m}$ ) located in the Region of Murcia, a semi-arid area of south-eastern Spain. The lagoon is isolated from the Mediterranean Sea by a 20-km-long ancient sandy bar (called La Manga). This area is now highly urbanized and five very shallow channels cross it exchanging its waters with the Mediterranean Sea. The territory is characterized by scarce precipitation $(<300 \mathrm{~mm}$ per year) which mainly occurs during storm events in autumn and winter.

This enclosed coastal sea has been subjected to the action of man during many decades (it should be noted that some of the anthropic activities such as mining in the surrounding area even date back to Roman times). For several centuries permanent settled populations have existed on its perimeter with fishing and salt mining activities. Moreover, as in the rest of Spain, mass tourism has urbanized a large part of its coast since the 1960s. A significant event for the territory was the establishment of the Tajo-Segura river transfer since the 1970s. This enabled the development of a very strong agriculture in the neighbouring area of the Campo de Cartagena. The area has currently become known as the "orchard of Europe". This global context of economic development around the lagoon has generated a varied catalogue of activities in which we can find ten marinas (including one of the largest in Europe, with 1700 mooring points), fishery and aquaculture, salt industry, military uses, an international airport, etc. that condition its natural balance, generating a complex management of the area (Fig. 1a).

Despite having represented an example of natural resilience to a sometimes hostile environment for decades (see for example Velasco et al., 2006; Martinez et al., 2007; Robledano et al., 2011 or MartinezLopez et al., 2014 and specially Perez-Ruzafa et al., 1991, 2000 and 2005), that situation recently changed radically. Since the summer of 2015 the existence of an intense process of eutrophication has substantially changed the traditional blue colour of its water to green, and turbidity has increased dramatically (Fig. 1b). The usual visibility passed from 1.5 to $2 \mathrm{~m}$ of depth to barely ten centimetres (measurements at similar times of the year of the light extinction coefficient $\mathrm{k}$ showed an increase from the usual values of about $0.1 \mathrm{~m}^{-1}$ to values higher than $1.1 \mathrm{~m}^{-1}$; IEO, 2016). This turbidity has led to a major change in the ecological status of the lagoon. For example, $85 \%$ of the vegetation cover of its seabed disappeared (Fig. 2) and singular species of the area, such as the Pinna nobilis (Fig. 1, marine reserve picture; the largest bivalve mollusc in the Mediterranean Sea) left. Apart from the environmental controversy, this situation has also generated significant social alarm (especially concerning the tourism industry), due to the special identification of the whole region with the lagoon. It is in this context that the managing of the Mar Menor is proposed and included as an Integrated Territorial Investment (hereinafter ITI) in the framework of European directives for integrated management for coastal territories (European Parliament, 2002) seeking to be the definitive tool to end the current problems. ITI is a new concept of management funding created by the European Commission for the resolution of complex issues during the 2014-2020 period. In addition to the usual requirements of the commission for transparency, publicity and sustainability of the actions carried out under its framework, the following questions are added: 1) it must address complex multidisciplinary geographically delimited issues; 2) the funds are not subsidies but cofinancing to ensure the real involvement of the administrations that apply for them; 3) they must be accompanied by an intense participatory process that involves all stakeholders of the problem; and finally 4) all these aspects must be integrated though a binding integrated management strategy for applicant administrations to guarantee the quality and sustainability of actions over time. In this sense, the Mar Menor area fitted within these boundary conditions perfectly. It was thus selected as a pilot project at environmental level by the European Commission for Spain, with the Integrated Management Strategy of the Mar Menor ITI (hereinafter Mar Menor ITI) being determined as the instrument for managing the entire process.

In such a context, the Mar Menor represents a double challenge for the ITI. On the one hand, it must solve the sudden change in the configuration of an ecosystem that maintained some stability for years. On the other hand, it must implement an integrated management framework for a governance that guarantees its continued recovery with a sustainable cohabitation between stakeholders and natural values. Therefore, a multidisciplinary approach configuring the Mar Menor as a complex socioecological system will be carried out. A DPSIR framework is proposed due to the expected large and heterogeneous number of stakeholders involved. The current issues of the Mar Menor are not only environmental but also address many different areas requiring an accurate analysis of land use policy linked to the lagoon. This framework will consequently be enhanced through the use of GIS tools. These instruments can provide interesting analysis of influence areas of lagoons configured as complex systems where the origins of their issues are diffuse or not easily attributed to any individual source (Garcia-Ayllon, 2017a). We will thus be able to determine sectors of preferential work. In this sense, GIS use, combined with the participatory process for the ICZM, is one of the innovations raised in the Mar Menor ITI, in what we could refer to as "GIS participatory mapping".

It must be noted that the Mar Menor has already counted on a significant number of management plans and protection regulations for many years, at regional, national and European level as part of the Natura 2000 network. Nevertheless, this situation has failed to prevent the progressive deterioration of the lagoon, whose management requires reconciling very different uses. Consequently, the Mar Menor ITI will be proposed as a new different model of ICZM. It will establish a tool able to environmentally recover the lagoon in the medium term and provide a sustainable management framework for the future, but necessarily maintaining an agreed cohabitation of pre-existing activities in order to involve all stakeholders.

\section{Methodology}

The working philosophy of the strategy for an integrated management of the Mar Menor in the ITI is based on the thesis of a comprehensive approach to all the lagoon's problems: from its environmental degradation to the issues arising from the excessive seasonality of tourism for example. In this sense, it must be recalled that it has been proposed as the application to a specific case, although the proposal is still an open methodology applicable to other areas with similar problems. One of the most innovative model approaches (versus the previous environmental plans performed), is the proposal of the lagoon and its influence areas as the so-called Socio Ecological System of the Mar Menor (hereinafter SESMM). It is a multidisciplinary concept for the ICZM Strategy in which the realization of an open, transparent and participatory process with no limitations is critical (Ballinger et al., 2010). In this context, the involvement of all the stakeholders in the drafting and subsequent management of the strategy is essential towards its implementation. The process is performed in four basic stages: 

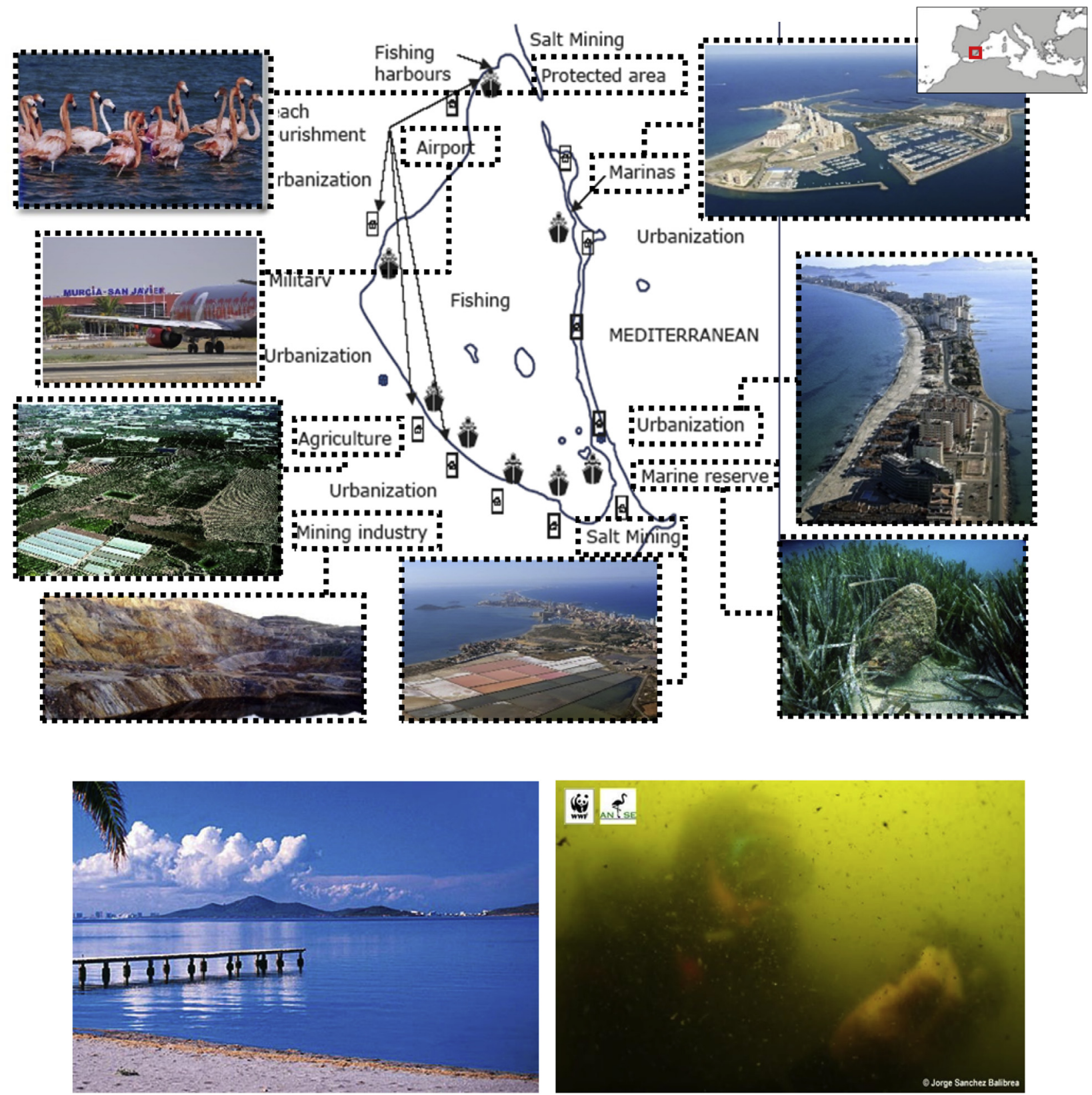

Fig. 1. a) Mar Menor catalogue of anthropic activities around the lagoon (upper) and b) turbidity change of its waters from its usual appearance for tourism to eutrophication phenomena (lower). Source: author, WWF and ANSE.

analysis, diagnosis, determination of objectives, and proposal of actions/programs. The method proposes in parallel a more operational approach to the resolution of current problems in the medium term and a more strategic approach to the development of sustainable management in the long term. Chronologically, the procedure is as shown in the following scheme (Fig. 3):

These four stages are grouped into two main phases of diagnosis and proposals, with the participatory process being transversal to the whole process. It must be underlined that the Mar Menor ITI is not proposed like traditional frameworks with excessive rigidity and a planned hierarchy of the process necessarily oriented in the long term. This often generates the social perception of being a purely theoretical framework lacking practical application. In this sense, smaller individual actions that have been positively valued during the diagnostic phase can be implemented in the short term, before being included and developed in the final programs and plans whose definitive implementation is oriented more to the long term. This approach stems from the European Commission's philosophy of co-financing rather than pure funding: for the ITI tool to be granted, administrations are required to have accomplished prior investment financed by the applicants to ensure a real commitment to solve a problem and not one contingent to the granting of funds. This is implemented without prejudice to the fact that all the shares have to be incardinated in a coherent way in a planned strategy following the constraints expressed in the introduction section.

In relation to the participatory process, in order to achieve a 


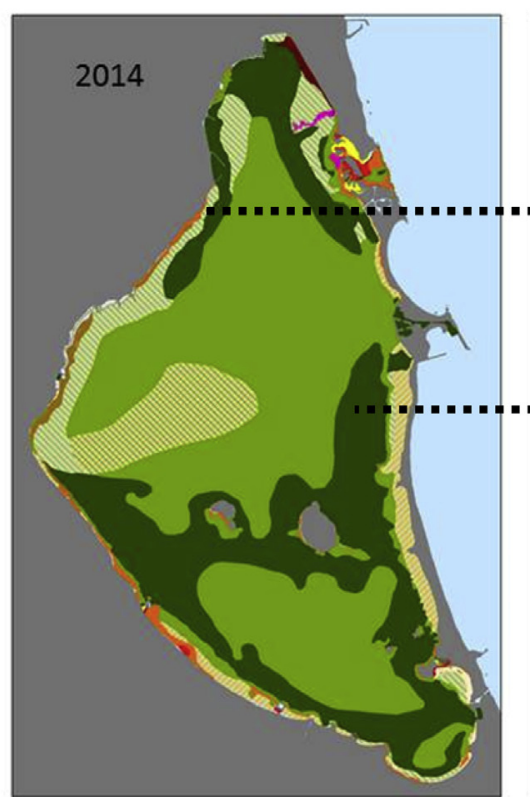

Cymodocea nodosa

Caulerpa prolifera

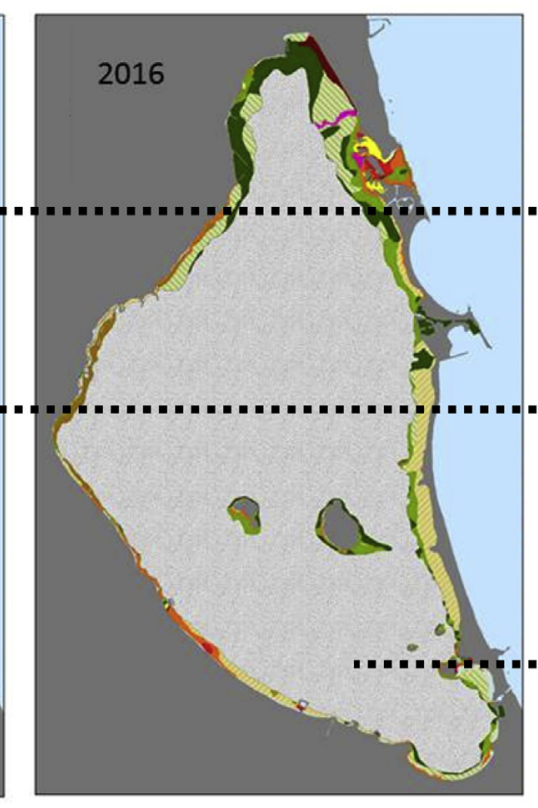

Mixed seagrass of $\mathrm{C}$. nodosa and C. prolifera No seagrass

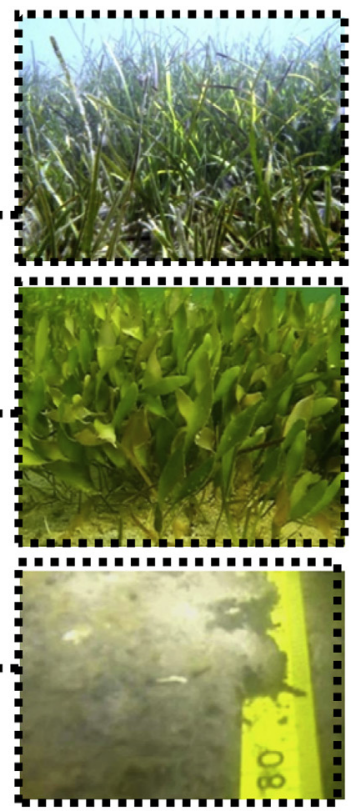

Scattered spots of $\mathrm{C}$. nodosa and / or C. prolifera

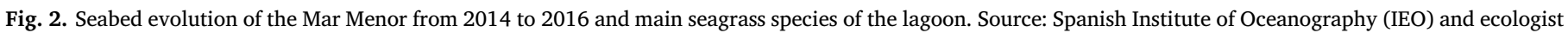
association ANSE.

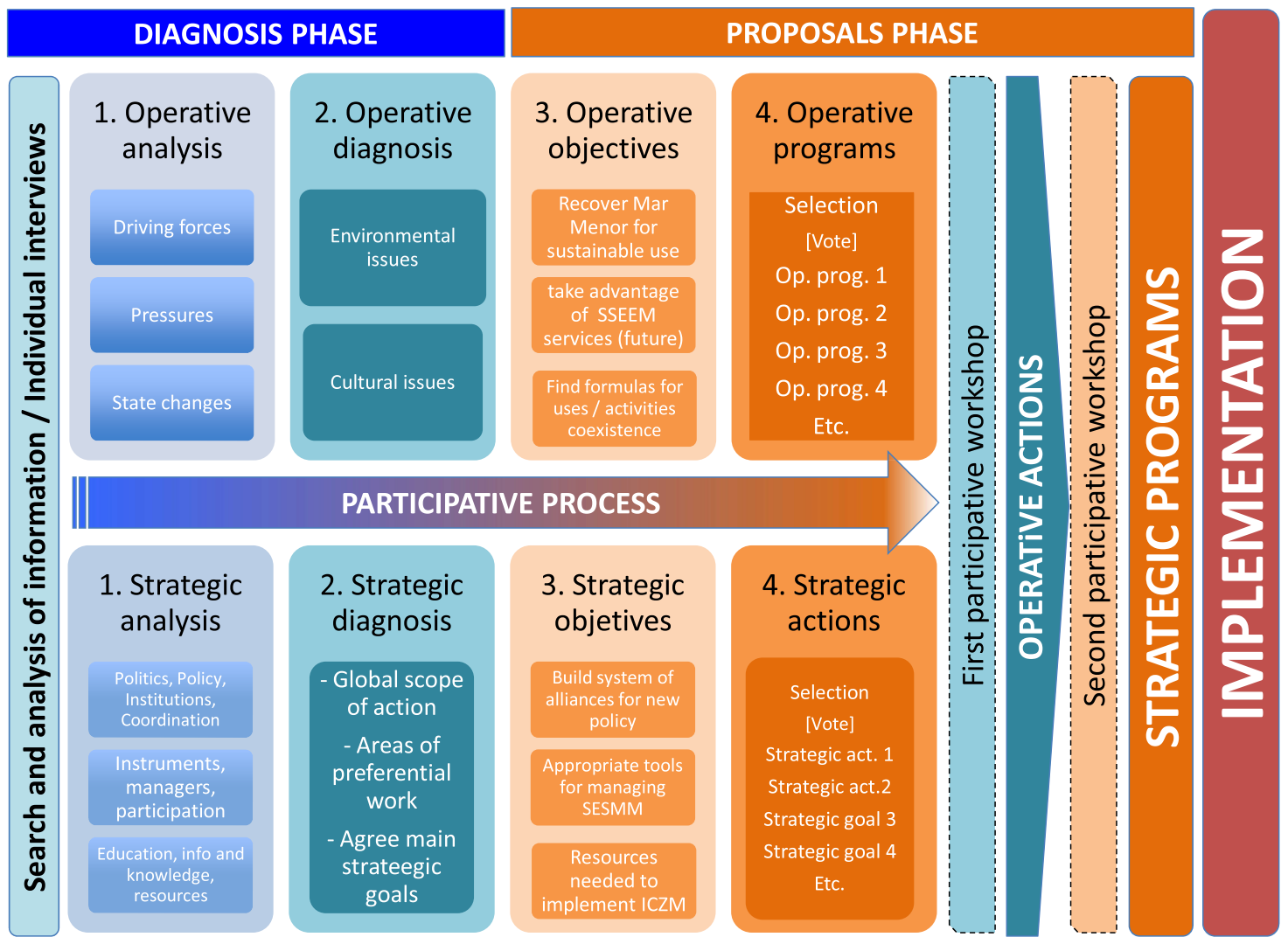

Fig. 3. Schematic configuration process of elaboration and implementation of the Mar Menor ITI. 
Table 1

Stakeholders who participated in the two main workshop sessions (number of members in parenthesis).

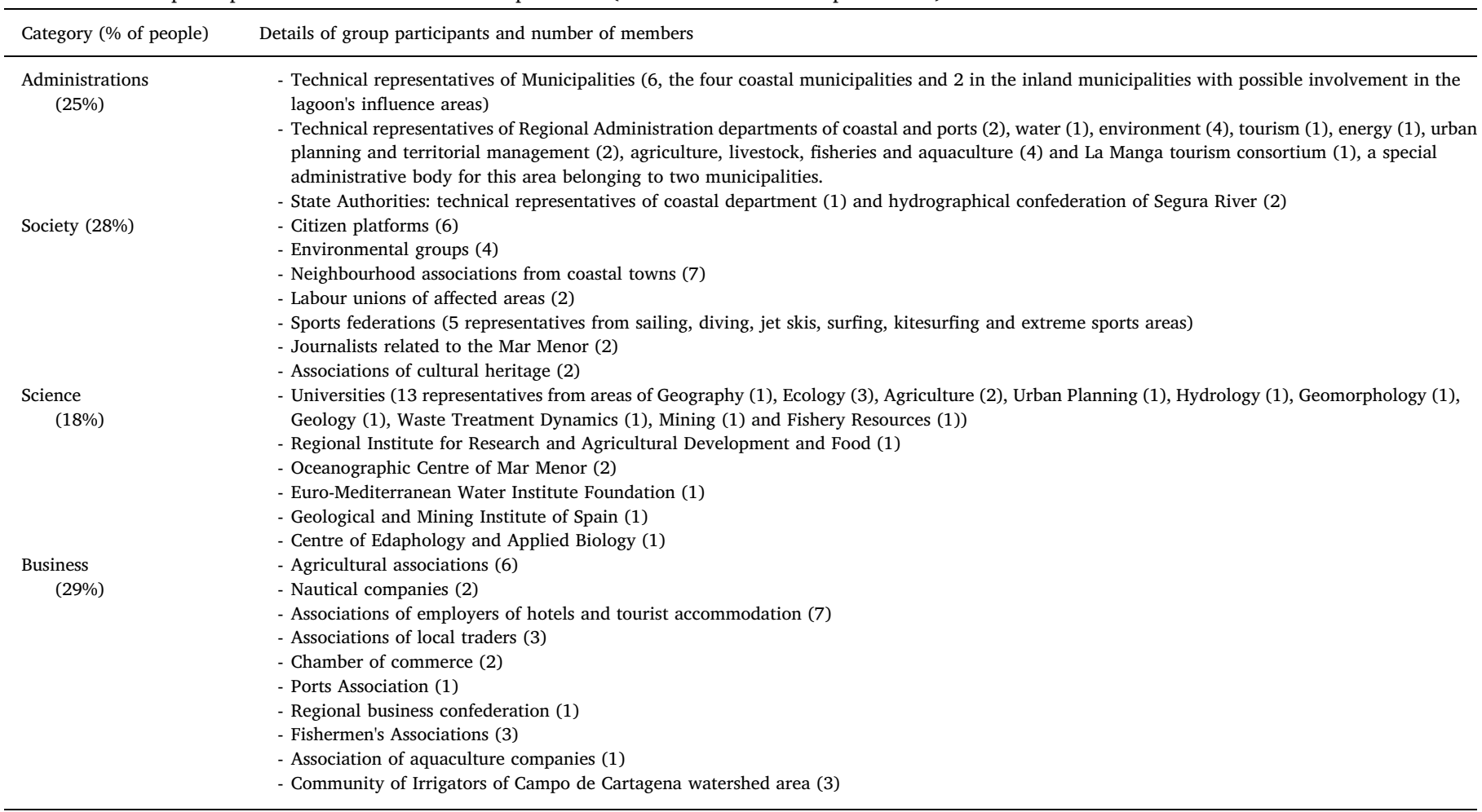

comprehensive participation of all stakeholders, two main workshops with all the existing stakeholders present have been developed, coinciding with the two main phases. The first was a common meeting aimed at establishing a consensual diagnosis answering questions such as: What situation are we currently in? What really are the main problems? Or what is the degree of severity/urgency of the problem? Subsequently, a second workshop proposed measures to implement in the governance of the Mar Menor (Where do we go now? How do we want the Mar Menor to be within 10 years?).

Prior to these global workshops, different interviews with all potential stakeholders were conducted to make an approximate envelope of all possible points of view and pre-diagnose all the necessary actors. This preliminary stage of the diagnostic phase is essential to prepare a basis document to make common workshops operational. We must bear in mind that these meetings will be multitudinous with more than 100 people with very different backgrounds and opinions. Thus, only those stakeholders that really have a necessary and legitimized link with the problems must be selected. The balanced choice of interest groups is also an important factor. It has to combine a representative enough sample of the interests of the society as a whole whilst holding enough technical knowledge of the subject so as not to discredit the results agreed upon (Barragán, 2011). In order to accomplish this task, four groups of stakeholders from the administrations, civil society, science/ technical fields and the business world were designed. Group categories should be distributed in a balanced manner and their members representative of sensitivities and interests within each category. This does not imply that groups must be numerically evenly distributed, but must reflect a realistic estimation of the responsibilities for the causes and solutions of issues, and those parts affected and interested by the current and future situation. In this case, the proportions of the four groups were respectively $25 \%, 28 \%, 18 \%$ and $29 \%$ as a result of the preliminary diagnosis of stakeholders obtained from individual interviews during the analysis stage (see Table 1 ).

The members of these four groups were distributed and rotated in another four work sessions during the diagnosis workshop that took place during a complete day. In this way, all groups have members of each of the four types of stakeholders, and every stakeholder has discussed in each of the four work sessions. The work sessions had a facilitator who guided the debate and was responsible for compiling the results that generated consensus or controversy on the topics listed in Table 2.

These results were used to elaborate a work document for the second workshop including proposals for actions and programs. Therefore, the second workshop must prioritize the different objectives detected, reflecting the different points of view. It should also propose the measures to be developed in the short, medium and long term, who should lead or manage those proposals, and which resources may be necessary to undertake them.

The consensus of the measures must not be the simple result of a majority vote of a list of proposals. Given the complex nature of the problem, the agreement of different goals should require certain sophistication to achieve the real commitment of all stakeholders. In this case, since these objectives involve setting priorities whose scope transcends different fields (political, economic, technical, legal, etc.), social priority matrixes have been established as tools for the selection of strategic actions and operational programs during the development of the second workshop. The matrixes (see details in the Appendix) are configured prioritizing nine specific objectives resulting from the work of the first workshop for the ICZM strategy according to three implementation criteria for strategic actions: 
Table 2

Configuration of the working groups, topics discussed and expected results in the first common workshop session.

\begin{tabular}{|c|c|c|c|}
\hline Group & Topics to be discussed & Guidance for debates & Expected results \\
\hline 1 & Operative diagnosis & $\begin{array}{l}\text { Socio-Ecological system in which human activities } \\
\text { need to be managed. } \\
\text { Driving forces: the levers of change } \\
\text { Pressures: how human activities are presented } \\
\text { Environmental changes: visible problems } \\
\text { Loss of ecosystem services and how they affect } \\
\text { human well-being }\end{array}$ & $\begin{array}{l}\text { Agreement or alternative consensus proposals on Socio- } \\
\text { Ecological System of the Mar Menor and delimitation of } \\
\text { the scope. }\end{array}$ \\
\hline 2 & Political diagnosis & $\begin{array}{l}\text { Public politics } \\
\text { Coordination-cooperation } \\
\text { Public participation } \\
\text { Institutions }\end{array}$ & $\begin{array}{l}\text { Agreement or alternative consensus proposals on } \\
\text { elements of the Decalog for ICZM aimed at a strategic } \\
\text { partnership to a new public policy. }\end{array}$ \\
\hline 3 & Socioeconomic diagnosis & $\begin{array}{l}\text { Normative } \\
\text { Strategic and operational instruments } \\
\text { Financial Resources } \\
\text { Knowledge } \\
\text { Training of managers, } \\
\text { Education for sustainability }\end{array}$ & $\begin{array}{l}\text { Agreement or alternative consensus proposals on } \\
\text { elements of the Decalog for ICZM intended to provide } \\
\text { more effective tools in public administration and } \\
\text { sufficient resources for integrated management model in } \\
\text { the SESMM }\end{array}$ \\
\hline 4 & $\begin{array}{l}\text { Basis for integrated management } \\
\text { strategy }\end{array}$ & $\begin{array}{l}\text { Key Issues for Human Welfare } \\
\text { Key issues for integrated management } \\
\text { SWOT: Operational and Strategic } \\
\text { Vision and Mission, principles, goals and } \\
\text { objectives }\end{array}$ & $\begin{array}{l}\text { Agreement or alternative consensus proposals on the } \\
\text { aspects that influence the proposals. }\end{array}$ \\
\hline
\end{tabular}

a) The importance and need for action for the strategy.

b) Urgency of action related to achieving the goal and targeting developments.

c) Motricity (dragging capacity that this action has on others, whether in relation to the goal and purpose where it is inscribed, or for other ones).

Additionally, there are three levels of development for introducing operational priorities to existing and proposed operative programs:

a) Leadership: start, drive and lead, the start of a program or action.

b) Approach: its function is to resolutely undertake a set of important actions of the strategy.

c) Deployment and Consolidation: this is the most complex from an operational point of view. It requires a greater amount of resources, both human and material, and is of a longer duration (several years) to carry out the corresponding actions.

Lastly, an important question will be exactly where the issues take place and where those operative measures have to be implemented (strategic actions are understood for the global SESMM). As will be seen in the analysis section, the spatial relationships and linkages of the lagoon with the different human activities are complex and sometimes interrelated (actions to undertake in urbanized coastal areas, nitrates contributions from agricultural crops, wadis, etc.). But, what do we mean by urbanized coastal area? Which crops contribute nitrates to the lagoon? What is the geographical scope of the measures? etc. In this sense, GIS analysis will be an important tool to enhance the ICZM by graphically expressing results and discussions from the participatory process relating to the real territorial scope of the ITI. This will enable areas of preferential work arising from the workshops to be created to implement different measures.

\section{Analysis and diagnosis}

Analysis of precedent models of strategic processes in deteriorated- threatened environments on coastal lagoons subjected to varied anthropic impacts is carried out prior to the workshops. Very interesting case-studies can be found in the Salton Sea in the USA (Glenn et al., 1999; Chattopadhyay and Bairagi, 2001) or in the Couronian Spit in Russia-Lithuania (Armaitiene et al., 2007). A singular and innovative aspect of the process developed in the Mar Menor ITI is, in addition to its GIS multidisciplinary approach, its vocation of conjugating the environmental recovery of the lagoon with its value enhancement for compatibility with economic development.

In this sense, a model was proposed to stakeholders in which the protection of the lagoon must not be at odds with its tourism development or agriculture. The working philosophy has been developed on the principle that the "zero alternative" (doing nothing) is not always the most environmentally sustainable alternative. Very illustrative cases of this problem were shown in the islands or some other places of the lagoon theoretically protected by the normative. There, the lack of management by the administration forbidding any activity that allows its monitoring and maintenance, has led to users' visits turning those islands occasionally into a trash dump.

On the other hand, the diagnosis during the participatory process has been performed from a positive approach. This is to seek the harmonization of all existing activities while maintaining the fragile natural balance of the lagoon so that all stakeholders voluntarily assume the decisions that are made to avoid them from becoming nothing more than mere theoretical postulates. In this context for example, agriculture is a strategic asset for the regional economy as it is a very competitive activity. As such there was no intention to reduce or eliminate such an element for the recovery of the lagoon, but rather to seek and provide the environment of corrective mechanisms to alleviate its effects.

Regarding the analyzed conceptual framework, during the first workshop a DPSIR scheme was proposed to use for diagnosis. DPSIR was proposed by the United Nations Program for the Environment in its "Global Environment Outlook" 2007, known under the acronym GEO-4, and was consolidated in the GEO-5 (United Nations, 2012). This conceptual framework has been updated collecting contributions by the 


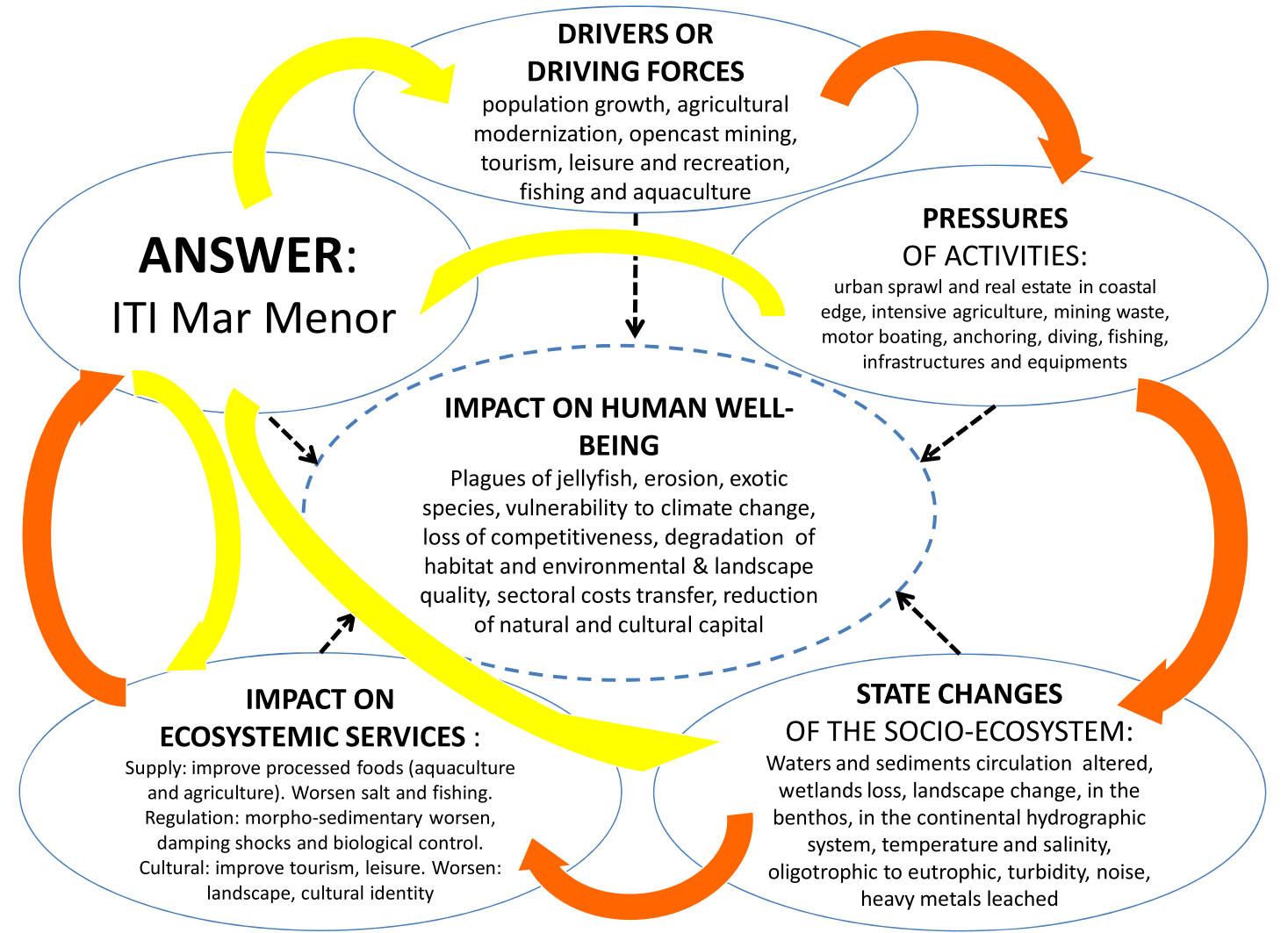

Fig. 4. DPSIR model adapted to SESMM for strategic diagnosis (inputs in orange and outputs in yellow). (For interpretation of the references to colour in this figure legend, the reader is referred to the Web version of this article.)

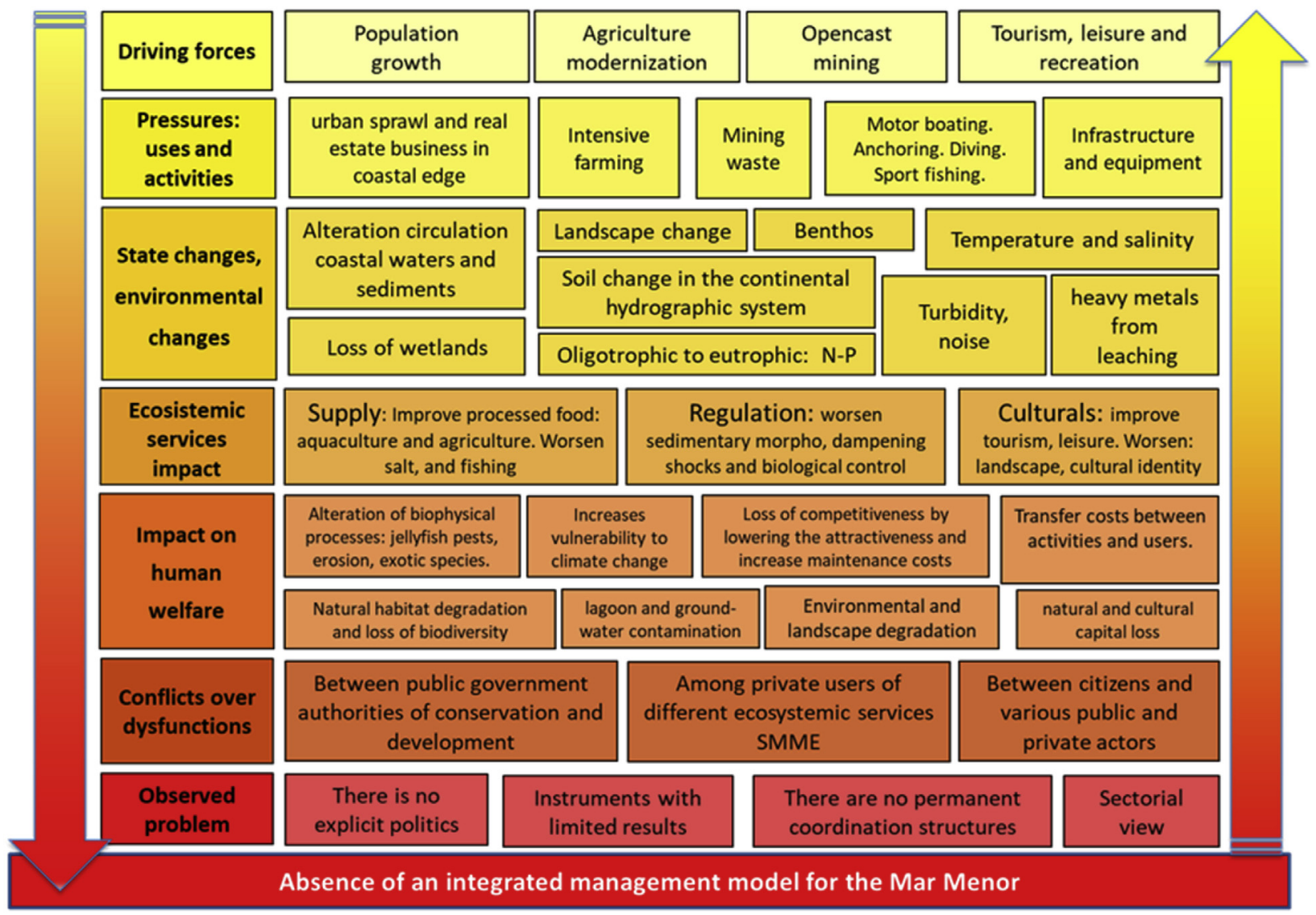

Fig. 5. Synthesis of $360^{\circ}$ operational diagnosis from the Mar Menor ITI Strategy. 


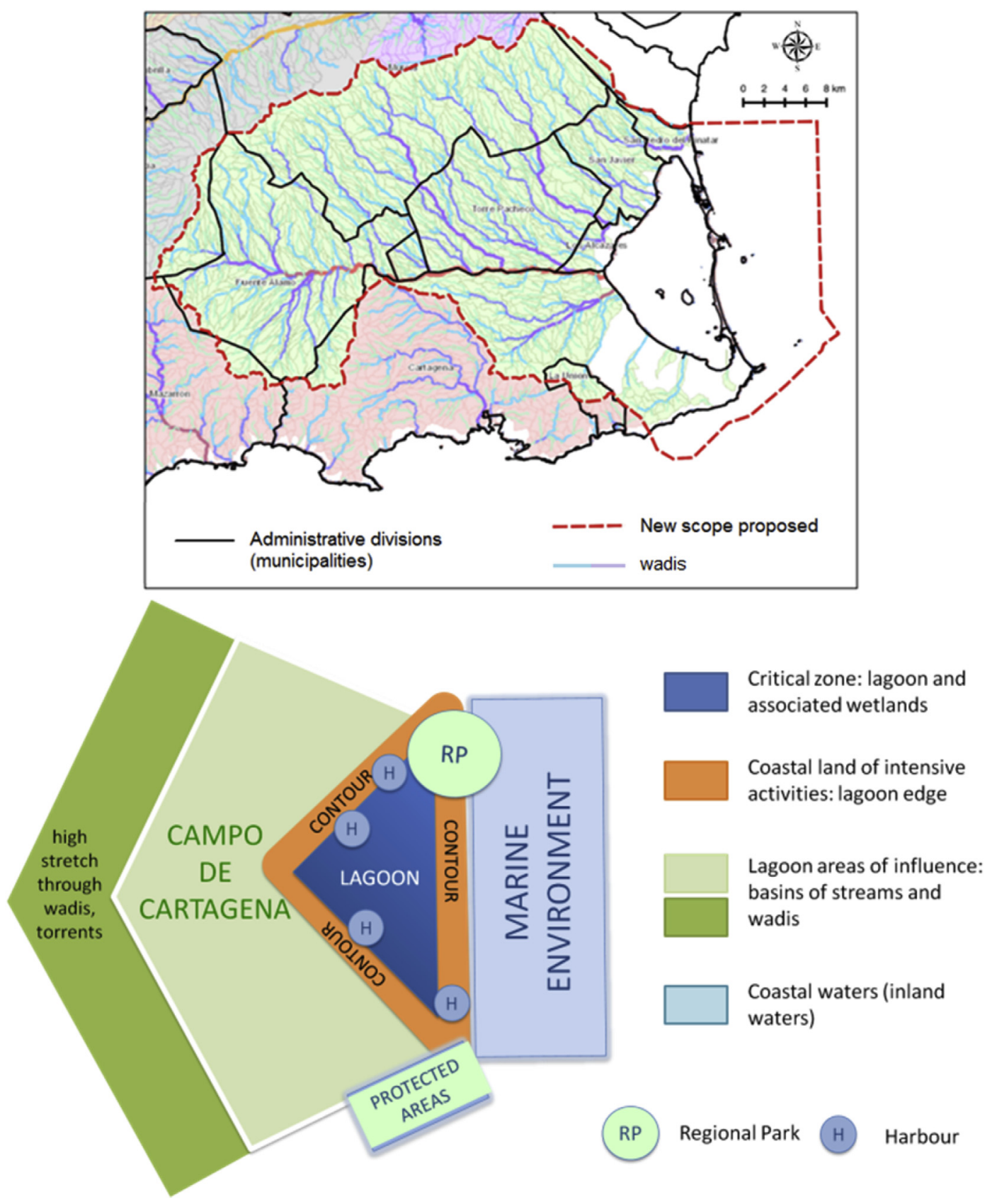

Fig. 6. GIS participatory mapping for the SESMM: final scope of action selected based on GIS multisectoral analysis during workshops (upper) and schematic representation of it including the four areas of preferential work proposed for actions and plans (lower).

Intergovernmental Panel on Climate Change (IPCC) and the Millennium Ecosystem Assessment (MEA), especially with regard to concepts such as human welfare and ecosystem services. The model, based on a process with five main sections, which relate to human beings and their environment, was adapted to SESMM during the first workshop (Fig. 4).

First, the number of driving forces (D) that mark the evolution of human development (economic, technological, social, political, demographic, etc.) were included. Economic and demographic factors are associated, in a very particular way, with what happens in coastal areas. The second stage sets the pressures $(\mathrm{P})$ that human intervention exerts in the environment and are manifested in: land use (e.g. changes caused by extreme urbanization on the ancient sandy strip called La Manga), harvesting or intensive resource extraction, emissions into the coastal marine (pollutants and waste), the introduction or removal of species and external inputs (e.g. fertilizers coming from intensive agriculture). The third deals with finding out the state and evolution of the environment (S): landscape degradation, loss of natural habitats, water pollution, alteration of coastal dynamics, etc. Thus major environmental changes were noted. Then the impacts (I) that affect human well-being, in some of its dimensions (safety, health, social relations, 
basic material needs) are analyzed. This required a prior analysis of how ecosystem services evolve (provisioning, regulating and cultural), with those outside the ecosystem (hydrocarbons, minerals, renewable energy), natural resources and stress factors (risks and threats). Finally, the responses (R), which consist in measures that mitigate or correct dysfunctions or deviations observed in relationship to the previous four sections will be developed in the results section.

This whole process was proposed within a comprehensive, multidisciplinary approach with the stakeholders in the four workgroups of the first main workshop. In order to establish an operational diagnosis capable of simultaneously integrating the various issues that orbit around the Mar Menor, a $360^{\circ}$ process was performed highlighting the need to develop a comprehensive management strategy for the Mar Menor. The synthesis of this integrated diagnosis agreed with stakeholders can be observed in Fig. 5:

One of the main conclusions of this integrated approach agreed in the diagnostic phase is the absence of comprehensive management tools in the Mar Menor. Many of the problems that exist today go beyond the actual scope of the lagoon itself, with their origins being locating inland, which is one of the main causes of the inefficiency of the environmental protection figures. Other questions agreed upon respond to cultural or operative issues related to the absence of coordination structures. It was therefore essential to broaden the scope of the analysis beyond the simple geographical boundaries of the lagoon.

For that, a multisectoral GIS implementation of different anthropic uses and activities enabled the establishment of a comprehensive scope of the influences facing the lagoon. Within this multidisciplinary assessment, the role of the contributions arriving from the Campo de Cartagena area annexed to the lagoon through different wadis is outstanding. In this point, the Albujon wadi was especially interesting with $59 \%$ of contributions from the seven main wadis of the lagoon (see supplementary data for GIS model of Albujon wadi and global scope).

Based on this GIS analysis covering fields as diverse as orography, geology, socio-economics or administrative issues and taking into account variables like urban planning forecasting, a new scope including the real area of influence of the lagoon was agreed upon during the first workshop. Moreover, four preferential work areas were proposed for developing solutions during the second workshop (Fig. 6).

\section{Results}

The purpose of an ICZM Strategy for the Mar Menor raises more than the question about what to do regarding the human activities that converge here. It is about, above all, proposing the best way to organize decision-making that leads to the sustainability of the socio-ecological system. The integrated diagnosis was clear in this regard during the first workshop for three main questions about which a general consensus was reached among stakeholders. First, in the Mar Menor and its area of influence there has been disagreement between different economic and social activities and institutional actors for decades. This has led to the current problems encountered in the lagoon and it is now necessary to build a system of alliances between major social and institutional stakeholders. Second, the future SESMM will need to adopt a specific instrument to manage it as part of an integrated management model. Lastly, in the current context, it is essential to provide and implement resources (not only financial but also knowledge, training and education) and evaluate the results achieved periodically to learn from and correct possible mistakes to guide this new model to success and to define a sustainable future for the Mar Menor.

These three main aims, called "strategic goals", were discussed and agreed upon by all the stakeholders during the diagnosis phase of the participatory process. Therefore, the most important efforts of this strategy must be directed to seeking a model of organization that is able to tackle multiple pending challenges for the Mar Menor in environmental, social and economical terms, and to channel it into specific objectives and concrete actions. This part, developed during the proposal phase in the second workshop, cannot be solved by a simple majority vote of a list of possible actions. It requires a more elaborate process to overcome possible controversies and avoid conflicts of interests between stakeholders. For that, 29 organizational performances proposed by stakeholders (called strategic actions or management tools) included in 9 specific objectives (A to H, 3 for each strategic goal) were discussed and assessed through what we have called "priority matrixes" for establishing importance, urgency and motricity criteria described in the methodology section (Fig. 7).

Within the first strategic main goal we have: A) the creation of new policies for the SESMM with the approval of the strategy in the official bulletin, the performance of a political commitment called the declaration of the Mar Menor and the boosting of existing or pending development actions through operational programs (see later in Fig. 8); B) extending executive coordination due to administrative dispersion of competences within the SESMM with the creation of a coordination unit (more political) and an interadministrative commission (more technical); and C) ensure SESMM management stands out as a model of real social participation with the creation of a Mar Menor forum open to all citizens, a directory for integrated management restricted to legitimate stakeholders, and the development of transparency tools for public periodical information associated to institutional ICTs (e.g. regional government web).

Within the second main strategic goal, proposals were voted to: D) have adequate administrative legal support for the SESMM with the approval of a governance law in the regional parliament, the elaboration of management rules by the government and the creation of a political commission with all groups for its monitoring; E) having specific institutions to manage the SESMM with an integrated office (administrative level) and a scientific advisory committee (technical level); and F) create or adapt instruments for the ICZM like the SESMM operational plan (Fig. 8), administrative simplification for better ICZM integration, and the development of a GIS balanced scorecard as a monitoring and evaluating system of the ITI.

Finally, within the third global strategic goal votes were cast on: G) the importance of implementing financial resources; $H$ ) having a technical body prepared for surveillance and training of the ICZM; and I) educating society with conferences, classrooms and an observatory of the Mar Menor. The 23 elements finally voted and approved will serve as indicators of compliance with the ICZM strategy of the ITI. The importance in the fulfillment of these indicators can be set according to the envelope covering the main interests of the four stakeholder categories shown in Fig. 7, where the final set of proposals in the strategic side is summarized, including detailed social priority matrixes (see the appendix for the complete process detail).

In this strategic side, the implementation and development of the ITI was performed using a model of "strategic management" and not a "strategic plan". Recognizing this difference could mark the success or failure of the initiative. For this reason, all that entails the incorporation of alliances and strategic partnerships, organizational structures and management platforms prevailed, at least in the first phase. This does not mean that traditional "management plans" including measures have been forgotten. For the operational side of the ICZM, the ITI philosophy of existing actions must be taken into account before the strategy's implementation and the approach of sustainable cohabitation of current human activities with the recovery process of the lagoon. 


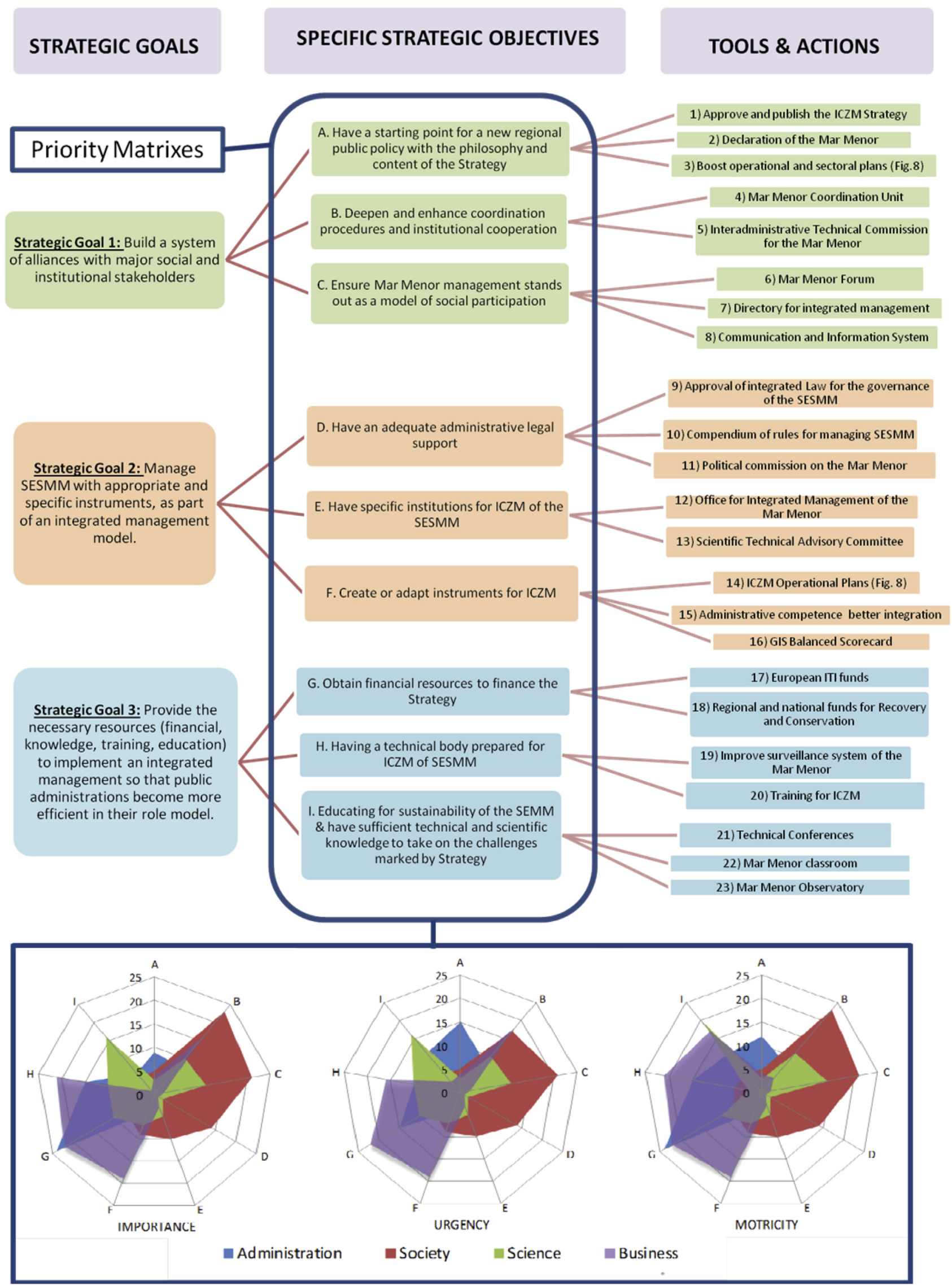

Fig. 7. Main strategic goals, specific objectives and actions of the ICZM strategy of the ITI of the Mar Menor (upper) and graphical summary representation of social priority matrixes envelopes obtained from stakeholders during the 2nd participatory workshop for specific strategic objectives (lower). 


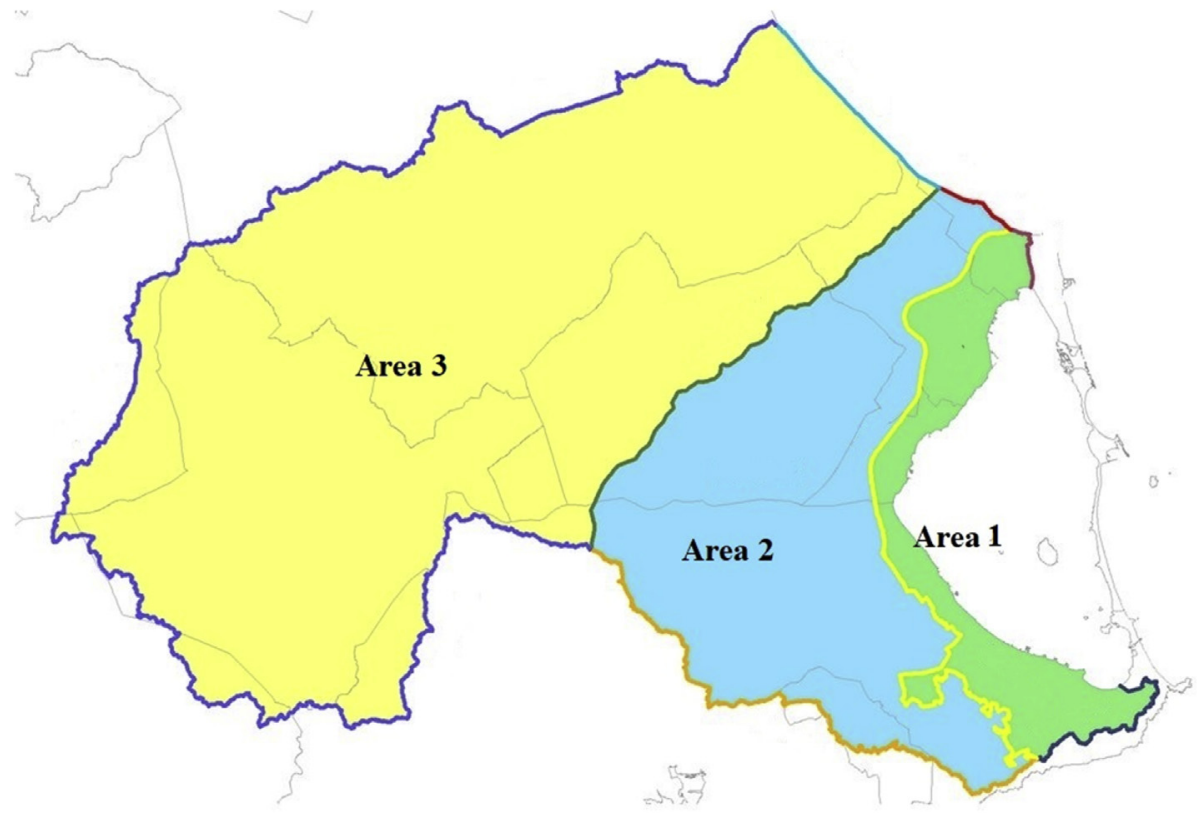

Fig. 8. Regulation of agricultural land uses in three zones: strict regulation (area 1), medium regulation (area 2) and basic regulation (area 3).

Consequently, operational objectives and programs have been embodied in the following sectoral plans and actions voted by the stakeholders during the second workshop of the participatory process. For that, "priority matrixes" were developed in votes with weighting of priorities and the sum of the previous criteria of importance, urgency and motricity, including the variable related to the level of development (see appendix). In this phase, it must be taken into account that operational actions proposed by stakeholders are not a closed list, and therefore may be subject to be extended, modified or reduced in the future by the actors created in the strategic part during the whole implementation of the ITI. This is part of the philosophy of the model that is considered as a living instrument which incorporates actions initiated prior to its implementation. Other actions may also be put in place after its implementation to adapt the changing conjuncture to which the lagoon may be subjected (for example the so-called "Lucifer effect" which involved an unprecedented increase in water temperatures for a prolonged period in summer 2017).

Another important aspect to consider is exactly where these measures are to be applied. Both sectoral plans and operational programs have been proposed distinguishing for their implementation among the four diagnosed areas in the first workshop in order to segment their scope of application. For the critical zone (the lagoon and associated wetlands) the update of management tools for the Natura 2000 network areas to the current issues was voted as a priority. But it was also voted as essential to start a plan focused in regulating existing activities (nautical, fishery, beach uses) and facilities (programs in order to rethink current infrastructures at a lagoon scale; for example, how to mitigate the impact in the coastal dynamics of breakwaters of the existing marinas that damage some beaches). Regarding coastal land with intensive activities (environment and lagoon edge) different work actions are aimed at adapting urban planning of the functional territory "Mar Menor-Campo de Cartagena area" to sustainable criteria. Regulating the urban density of residential uses in the vicinity of the lagoon, avoiding the urbanization of the gaps in the conurbation of the lagoon ring, improving the urban quality of the built-up areas requalifying the tourist areas, encouraging hoteliers uses, etc. were proposed and voted through the multioptional vote criteria with different weights of social priority matrixes.

The areas of influence of the lagoon have been the most difficult to determine technically and thus the contribution of the GIS approach has been more interesting (see supplementary GIS data). For these areas, four specific operational programs were voted on. Three were oriented to flood risk management, environmental recovery of ancient mining areas and forestation of mountain ranges against erosion. The fourth program was called "watershed zero contributions" to collect contributions from agriculture and study the hydrological and hydrogeological linkage of the agricultural surface (which are not necessarily one and the same) with the lagoon. This program was especially important since it implements in the "Campo de Cartagena" area the necessary hydraulic infrastructures to stop the arrival of nitrates. It also introduces new regulations in agriculture by dividing this territory into three areas with different degrees of impact depending on its proximity and linkage to the lagoon (see supplementary GIS data and Fig. 8). In this way, the engineering vision of infrastructure development to curb the impacts is combined with the environmental vision of regulating land uses in agriculture. Lastly, different programs regarded diving, the special treatment to the islands and marine reserves and climate change issues were included for the marine environment. All this process with its social priority matrixes detailed results is summarized in Fig. 9.

\section{Discussion: challenges to face towards a sustainable model of governance in the Mar Menor}

Coastal lagoons are sometimes complicated to define even within the European Water Framework Directive itself (Perez-Ruzafa et al., 2011). Their complex areas of influence and the multiple actors involved as transitional waters between the sea and the land make them territories which are difficult to manage. The Mar Menor was regulated 


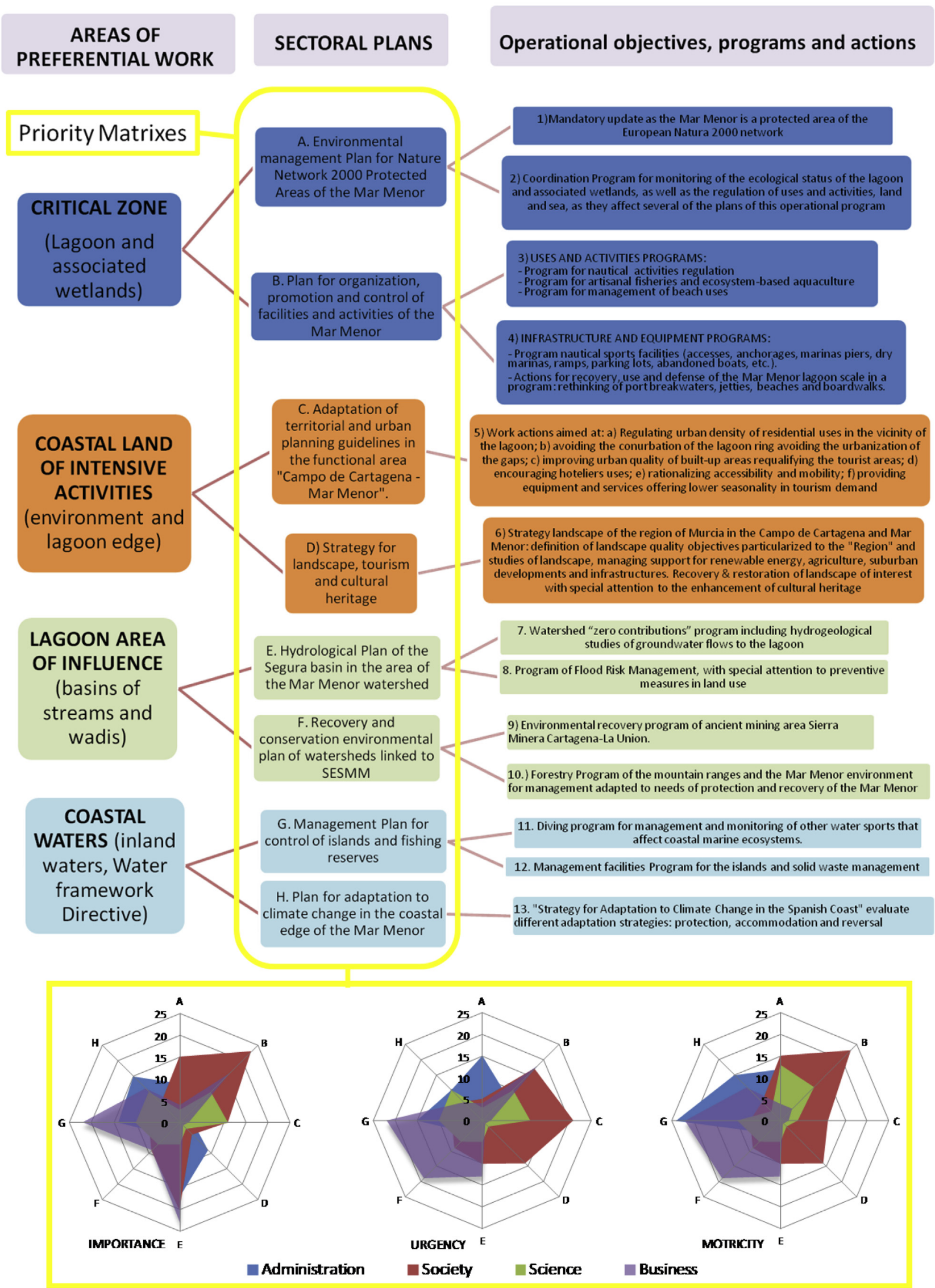

Fig. 9. Operational programs in the four work areas obtained from the development of the workshop (upper) and sectoral plans with their priority matrixes votes summarized (lower). 


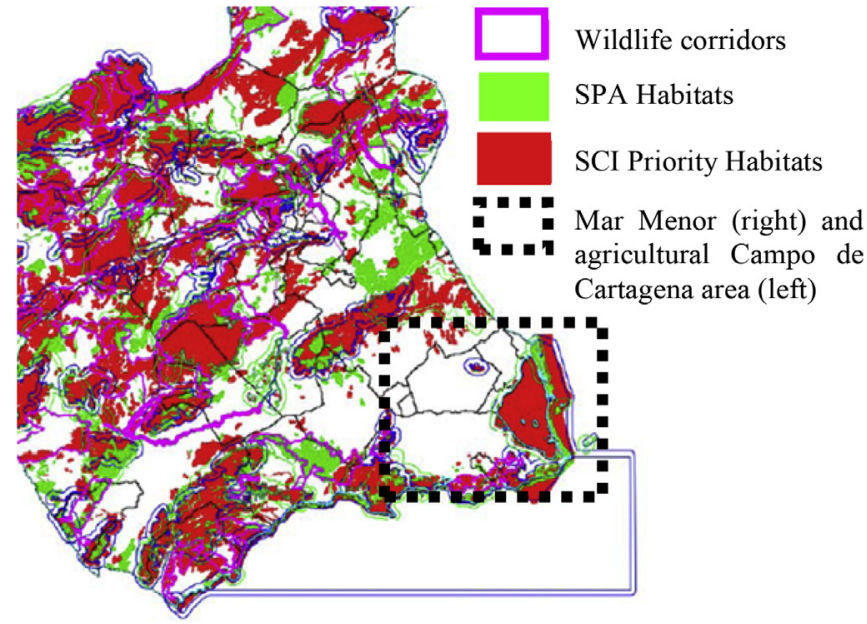

Fig. 10. GIS overlapping of all environmental protected areas and tools from the Natura 2000 network in the Region of Murcia.

by numerous environmental protection tools, specially from the Natura 2000 network (see appendix). Despite all of this, a catastrophic sudden situation occurred in 2015, although clear indicators of imbalances such as for example the overpopulation of Cotylorhiza Tuberculata jellyfish have long existed (these jellyfish were nourished by contributions from agriculture to the lagoon, Garcia-Ayllon, 2017b). Can we therefore say that the existing instruments of environmental protection failed? Not exactly. Rather, it may be necessary to reflect on whether these traditional protection and management instruments are currently adapted to complex environments such as the Mar Menor and its influence areas with a high level of human activity.

It is particularly interesting to observe how, near the surface area of the lagoon, which is strongly protected by several regional, national and European overlapping tools of environmental protection, we can find an annexed crop area called the "Campo de Cartagena". This area was not subjected to any environmental instrument and is where a great deal of the agricultural inputs that generate the problem of nitrates in the waters of the lagoon are originated. This context is reasonable insofar as this important agricultural area does not have any intrinsically environmental value on its surface (Fig. 10). Although this led to the paradoxical situation of having an environment like the Mar Menor that, despite having maximum environmental protection, has a critical threat position, forcing to rethink how to address its management tools. In this sense, it can be said that the ICZM model proposed by the Mar Menor ITI based on the SESMM solves the shortcomings of the previous instruments. Even so, we must take into account that for agricultural contributions alone for example, the issues are not limited to wellknown superficial contributions through wadis, but must also be analyzed from the hydrogeological perspective due to the nitrification of the aquifers and the underground runoffs.

A future challenge to be faced will be the real sustainable cohabitation between the various existing activities presenting some connection with the lagoon. In this field, one of the advances of the Mar Menor ITI in relation to the existing management tools is its vocation of comprehensive management beyond the simple environmental issues of the lagoon. The socio-ecological system proposed sets up a governance framework in which potential conflicts of interest between the different actors are resolved. In order to involve stakeholders in the process in a loyal way, and given that it was a problem of diffuse anthropization in which there was no single focus of problems but there is a large number of pre-existing activities with greater or lesser responsibility in the problems of the lagoon, a punitive process was not considered. This question responds to a more political rather than a technical decision, but in the author's opinion it was correct in the current context. The positive approach of the strategy has allowed us to weave a previously inexistent system of alliances between sectors, building a process that starts from the public investment for the start-up. Nevertheless, in the future it will require the public-private collaboration partnership among actors within the framework of constituted governance for its management and maintenance. In this moment, it will be important to address the concepts of cost transfer between sectors (Subirats et al., 2012) and willingness to pay (Tuan et al., 2014) because of the cross impact between sectors (the main sector to be taken into account is that the lagoon is a natural asset of all citizens). In this sense, the educational section of the strategy will have to play an important preparatory role able to capillarize this philosophy into all sectors of society.

Finally, another important future challenge for the lagoon will be to see if the coordination that the ITI establishes is really achieved. That is why so much emphasis has been put on the organizational part of the strategy, due to the problematic of Spanish administrative competency segmentation in complex environments such as the Mar Menor. Once all the stakeholders assume and agree on the ITI's philosophy of maintaining a sustainable coexistence between pre-existing activities, generating the necessary elements to eliminate the current impacts, then the technical solutions to implement are more or less clear, if the necessary resources are available. One such example is the development of collectors from the "zero discharge" program which collect contributions from agriculture that reach the lagoon through wadis to take them to treatment stations and then pour them into the Mediterranean Sea. On the one hand, it should be highlighted that a different approach would have been to totally or partially replace the current intensive agriculture of the area with another type of agriculture to eliminate the nitrates that cause turbidity, but that would imply an approach that differs from that of the ITI, which would surely have motivated major controversy among the stakeholders. On the other hand, when developing these collectors, we will face the administrative complexity of implementing solutions. This is because the management of wadis corresponds to the state authorities, while the public and private lands that they go through would require the necessary municipalities authorizations, with the environmental study to authorize its layout and discharge corresponding to the regional administration. Therefore, merely the design of this program for example will require intense coordination between administrations to avoid delays in implementing this operational action (similar contexts will be found in many other programs, such as the implementation of permanent surveillance in the lagoon for the elimination of illegal moorings or flood risk management affecting several coastal locations).

\section{Conclusions}

The traditional tools of environmental planning and management may be insufficient in areas of high natural value subject to contexts of intense diffuse anthropization, such as coastal lagoons. In the work carried out, the Mar Menor ITI has been presented as a new management model based on the sustainable preservation of the natural values of these environments through cohabitation with pre-existing human activities. The method based on the development of a $360^{\circ}$ DPSIR integrated diagnosis in a first phase clearly shows the need to establish a scope of action that is much broader than the lagoon itself. The second 
phase, agreed upon with stakeholders by using social priority matrixes, has revealed the need to implement 13 sectoral plans in this new scope to reverse the current situation, but also 23 strategic actions to ensure sustainable governance in the future.

To guarantee the real commitment of all stakeholders in the project, the Socio-Ecological System of the Mar Menor (SESMM) has been developed through a GIS participatory mapping process. On the one hand, the results demonstrate the importance of implementing mechanisms that bring together the full participation of all stakeholders in the management of complex environments such as coastal lagoons. On the other hand, the degree of consensus reached with this approach made in proposing positive formulas from a non-punitive optic, but rather regulatory from a multidisciplinary coordination approach, shows its validity for complex contexts of diffuse anthropization.

\section{Acknowledgments}

This work gathers the experience of the author as coordinator of the Integrated Territorial Investment project of the Mar Menor during the last two years. The author would like to thank the institutional support for the project of the Government of the Region of Murcia through its president P.A. Sanchez and its regional minister F. Bernabé, the collaboration of officials, technical teams and experts of renowned prestige such as J.M. Barragán and A. Perez-Ruzafa, and the participation and commitment with the project of all the stakeholders such as local and state administrations, citizen platforms, business associations, scientific institutions or environmental groups.

\section{Appendix A. Mar Menor existing regulations and participatory process details}

\section{A.1. Mar Menor pre-existing regulations}

Table A.1

Current legislative and policy environmental figures of protection in the Mar Menor lagoon.

\begin{tabular}{|c|c|c|c|c|}
\hline Protected area & Protection tool & Municipalities concerned & $\begin{array}{l}\text { Surface } \\
\text { (Ha) }\end{array}$ & Protection Regulations \\
\hline ES6200006 & $\begin{array}{l}\text { Terrestrial } \\
\text { ASCI }\end{array}$ & Cartagena, Los Alcazares and San Javier & 1073 & Directive 92/43/EEC \\
\hline ES6200030 & Marine ASCI & $\begin{array}{l}\text { S. Pedro del Pinatar, Cartagena, Los Alcazares } \\
\text { and San Javier }\end{array}$ & 13,446 & Directive 92/43/EEC \\
\hline ES0000260 & SPA area & $\begin{array}{l}\text { S. Pedro del Pinatar, Cartagena, Los Alcazares } \\
\text { and San Javier }\end{array}$ & 14,413 & Directive 2009/147/EC \\
\hline Salt flats and sands of S. Pedro & Regional Park & S. Pedro del Pinatar and S. Javier & 856 & $\begin{array}{l}\text { 4/92 Act PORN Decree } \\
\text { 44/1995 }\end{array}$ \\
\hline Cabezo Gordo & $\begin{array}{l}\text { Protected } \\
\text { landscape }\end{array}$ & Torre Pacheco & 281 & 4/92 Regional Act \\
\hline Open spaces and islands of the Mar Menor & $\begin{array}{l}\text { Protected } \\
\text { landscape }\end{array}$ & Cartagena, Los Alcazares and San Javier & 1186 & 4/92 Regional Act \\
\hline
\end{tabular}

\section{A.2. Participatory process technical data}

Table A.2.1

Participants.

Individual interviews with possible stakeholders First common workshop (integrated diagnosis)

Second common workshop (proposals)

Final number of members involved during whole ITI 1 coordinator/9 political posts from government/ 2 consulting teams made up of 7 people process [May 2015-March 2017]

Publication of the strategy through the office of citizen participation \& transparency

Public exposure for claims in the official bulletin
64 interviews [November/December 2015]

100 stakeholders invited/104 attendees [February 2016]

(April 2016] for the assembly of the workshops and the elaboration of the documents/ 1 scientific expert for the advice of the political balanced scorecard/ 5 regional government officials for documents oversight/147 different stakeholders 741 citizens participated by filling out different surveys to comment on the results and implementation of the strategy [April-September - November 2016]

124 claims of private individuals filed during the period of public exposure for drawing up the final document [December 2016, 124 vs. 5472 of last environmental tool of Mar Menor exposed without previous participatory process] 


\section{A.2.2 Voting systems for workshops}

The new scope of action and the four areas of preferential work were agreed schematically during the first workshop. Mapping details and the proposals from the four work groups of the first workshop were channeled into a work document presented in the second workshop for implementation through strategic and operational actions. These strategic and operational actions were voted and agreed upon by the stakeholders through a weighted vote of value 1, 2 or 3 (three for the highest priority and one for the minimum). Voting was done by applying three colored adhesive chips on a panel with all the proposals resulting from the first workshop for each of the three priority criteria (importance, urgency, motor), so that if a stakeholder did not place a record in an action for any of the three criteria, it was interpreted that such action had not sufficient relevance or that this stakeholder was not in agreement with this proposal of action. In addition, the stakeholders had to be selective in the use of the points since these were not unlimited, but each had only 40 points to distribute as they saw fit.

As can be seen in Figs. 7 and 8, the valuation of the three criteria by applying the selective voting weights in each of the actions by each of the four types of stakeholders (what we have called social priority matrices as being a two-dimensional structured vote), have very different values among the four types of stakeholders, even at the level of strategic objectives and sectoral plans in which the actions are grouped. This heterogeneous distribution is reasonable due to the different interests and perceptions of the reality of the four groups, but its envelope has served to propose a jointly agreed global proposal (for example, for the strategic actions, 29 actions were proposed as a result of the first workshop, finally through the system of priority matrices six were discarded that failed to meet a minimum of $5 \%$ of interest [normal distribution assumed] and one seventh was reformulated, see Fig. A.2.2).
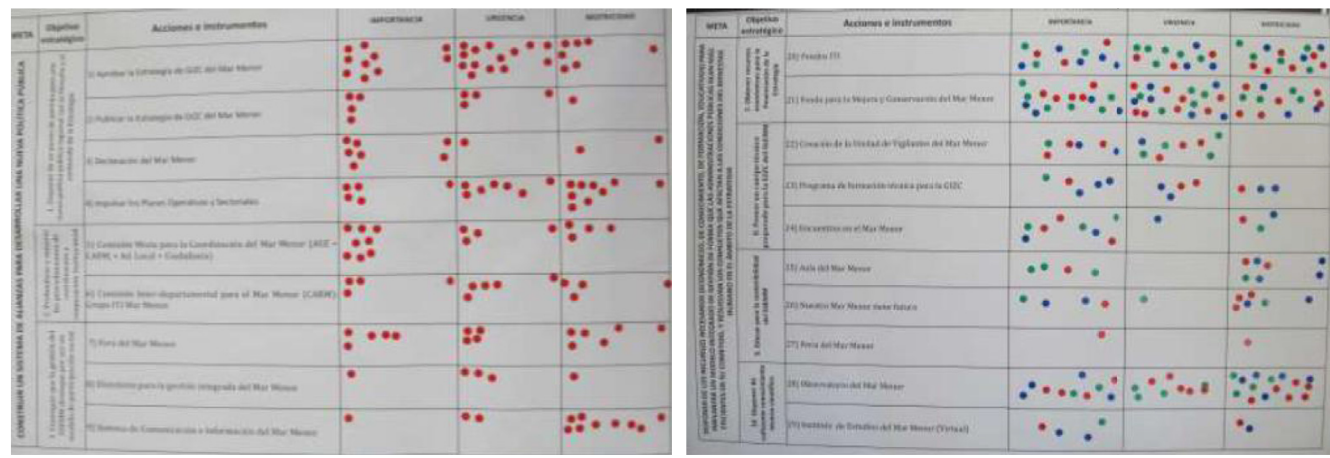

\begin{tabular}{|c|c|c|c|c|c|c|c|}
\hline $\begin{array}{l}\text { Strategic } \\
\text { action } \mathrm{n}^{\circ}\end{array}$ & $\begin{array}{l}\text { Final total } \\
\text { weighted votes }\end{array}$ & $\begin{array}{l}\text { Equivalent } \\
\text { priority level }\end{array}$ & \multicolumn{5}{|c|}{$\begin{array}{l}\text { Points table of the } 2^{\text {nd }} \text { workshop for strategic actions (green chips } \\
\text { in strategic goal } n^{\circ} 2 \text {, initial actions } 10 \text { to } 19 \text {, finally } 9 \text { to } 16 \text { ) }\end{array}$} \\
\hline 10 & 42 & 3 & & 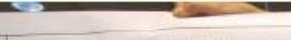 & & & \\
\hline 11 & \multirow{2}{*}{\multicolumn{2}{|c|}{ Action discarded by $2^{\text {nd }}$ workshop }} & 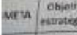 & Acconses o instrumeat os & meanosian & uneasen & moseations \\
\hline 11 & & & \multirow{3}{*}{ if } & 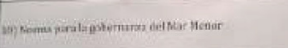 & $\because \because \because \because$ & $\therefore \because \because \because$ & $\because \because \vdots:$ \\
\hline 12 & \multicolumn{2}{|c|}{ Action discarded by $2^{\text {nd }}$ workshop } & & 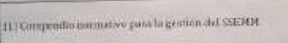 & - & & \\
\hline 13 & \multicolumn{2}{|c|}{ Action discarded by $2^{\text {nd }}$ workshop } & & 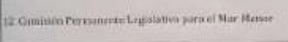 & & & \\
\hline 14 & 15 & 2 & \multirow{3}{*}{ 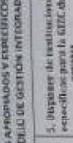 } & 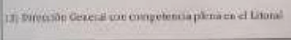 & $\bullet$ & - & \\
\hline 15 & 12 & 1 & & 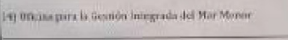 & $\because \because: \because$ & $\therefore \therefore \because$ & $\because$. \\
\hline 16 & 26 & 3 & & 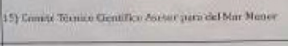 & $\because \because$ & - $\bullet$ & $\because \cdots$ \\
\hline & \multirow{2}{*}{\multicolumn{2}{|c|}{ Modified action by $2^{\text {nd }}$ workshop }} & & 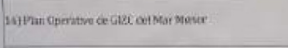 & $\because \because \because$ & $\therefore \because \because$ & $\because \therefore \bullet$ \\
\hline 17 & & & \multirow{3}{*}{ Her } & 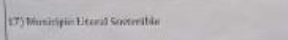 & - & $\cdots$ & - \\
\hline 18 & \multicolumn{2}{|c|}{ Action discarded by $2^{\text {nd }}$ workshop } & & 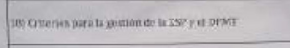 & $\cdots$ & $\because$ & \\
\hline 19 & 44 & 3 & & 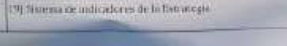 & & 0 & $\because \because \because \%$ \\
\hline
\end{tabular}

Fig. A.2.2. Example of weighted voting of three criteria for strategic actions: red chips for strategic goal $\mathrm{n}^{\circ} \mathbf{1}$ (upper left), final position of chips for strategic goal $\mathrm{n}^{\circ} 3$ (upper right) and detailed results for green chips for strategic goal no2 (lower).

\section{Appendix B. Supplementary data}

Supplementary data related to this article can be found at http://dx.doi.org/10.1016/j.ocecoaman.2018.05.004.

\section{References}

Armaitienė, A., Boldyrev, V.L., Povilanskas, R., Taminskas, J., 2007. Integrated shoreline management and tourism development on the cross-border World Heritage Site: a case study from the Curonian spit (Lithuania/Russia). J. Coast. Conserv. 11 (1), $13-22$.

Ballinger, R., Pickaver, A., Lymbery, G., Ferreria, M., 2010. An evaluation of the implementation of the European ICZM principles. Ocean Coast. Manag. 53, 738-749.
Barragán, J.M., coord, 2011. Integrated Coastal Management and Public Policy in Latin America: Proposals for Action. Red IBERMAR (CYTED), Cádiz, pp. 280.

Bellio, M., Kingsford, R.T., 2013. Alteration of wetland hydrology in coastal lagoons: implications for shorebird conservation and wetland restoration at a Ramsar site in Sri Lanka. Biol. Conserv. 167, 57-68.

Boyle, R.H., 1996. Life, or death, for the Salton Sea (the plight of California's otherworldly sea). Smithsonian 27, 86-97.

Casini, M., Mocenni, C., Paoletti, S., Pranzo, M., 2015. Decision support system development for integrated management of European coastal lagoons. Environ. Model. 
Softw. 64, 47-57.

Chattopadhyay, J., Bairagi, N., 2001. Pelicans at risk in Salton Sea - an eco-epidemiological model. Ecol. Model. 136, 103-112.

Conde, D., Vitancurt, J., Rodríguez-Gallego, L., de Álava, D., Verrastro, N., Chreties, C., Solari, S., Teixeira, L., Lagos, X., Piñeiro, G., Seijo, L., Caymaris, H., Panario, D., 2015. Solutions for sustainable coastal lagoon management: from conflict to the implementation of a consensual decision tree for artificial opening. Coast. Zones 13, 217-250.

De Wit, R., Rey-Valette, H., Balavoine, J., Ouisse, V., Lifran, R., 2017. Restoration ecology of coastal lagoons: new methods for the prediction of ecological trajectories and economic valuation. Aquat. Conserv. 27, 137-157.

Domingues, R., Guerra, C., Barbosa, A., Galvão, H., 2017. Will nutrient and light limitation prevent eutrophication in an anthropogenically-impacted coastal lagoon? Cont. Shelf Res. 141, 11-25.

European Parliament \& Council, 2002. Implementation of integrated coastal zone management in Europe. Off. Bull. L 148 of 06/06/2002 p. 0024 - 0027.

Fiandrino, A., Ouisse, V., Dumas, F., Lagarde, F., Pete, R., Malet, N., Le Noc, S., De Wit, R., 2017. Spatial patterns in coastal lagoons related to the hydrodynamics of seawater intrusion. Mar. Pollut. Bull. 119, 132-144.

Garcia-Ayllon, S., 2017a. Integrated management in coastal lagoons of highly complexity environments: resilience comparative analysis for three case-studies. Ocean Coast. Manag. 143, 16-25.

Garcia-Ayllon, S., 2017b. Diagnosis of complex coastal ecological systems: environmental GIS analysis of a highly stressed Mediterranean lagoon through spatiotemporal indicators. Ecol. Indic. 83, 451-462.

Glenn, E.P., Cohen, M.J., Morrison, J.I., Valdés-Casillas, C., Fitzsimmons, K., 1999. Science and policy dilemmas in the management of agricultural waste waters: the case of the Salton Sea, CA, USA. Environ. Sci. Policy 2 (4-5), 413-423.

IEO, Spanish Institute of Oceanography, 2016. Report Data for Chlorophyll and Turbidity in August 2016. Canal Mar Menor. http://canalmarmenor.es/informacion-tecnicocientifica-del-mar-menor/.

Leruste, A., Malet, N., Munaron, D., Derolez, V., Hatey, E., Collos, Y., De Wit, R., Bec, B., 2016. First steps of ecological restoration in Mediterranean lagoons: shifts in phytoplankton communities. Estuar. Coast. Shelf Sci. 180, 190-203.

Martinez, J., Esteve, M.A., Martínez-Paz, J.M., Carreño, F., Robledano, F., Ruiz, M., Alonso, F., 2007. Simulating management options and scenarios to control nutrient load to Mar Menor, Southeast Spain. Trans. Waters Monogr. 1, 53-70.

Martínez-López, J., Carreño, M.F., Martínez-Fernández, J., Esteve, M.A., 2014. Wetland and landscape indices for assessing the condition of semiarid Mediterranean saline wetlands under agricultural hydrological pressures. Ecol. Indic. 36, 400-408.

McFadden, L., Schernewski, G., 2014. Critical reflections on a systems approach application in practice: a Baltic lagoon case study. Reg. Environ. Change 14 (6), 2115-2126.

Mitchell, S., Boateng, I., Couceiro, F., 2017. Influence of flushing and other characteristics of coastal lagoons using data from Ghana. Ocean Coast. Manag. 143, 26-37.

Newton, A., Icely, J., Cristina, S., Brito, A., Cardoso, A.C., Colijn, F., Dalla Riva, S., Gertz, F., Hansen, J.W., Holmer, M., Ivanova, K., Leppäkoski, E., Canu, D.M., Mocenni, C., Mudge, S., Murray, N., Pejrup, M., Razinkovas, A., Reizopoulou, S., Pérez-Ruzafa, A., Schernewski, G., Schubert, H., Carr, L., Solidoro, C., Viaroli, P., Zaldívar, J.M., 2014. An overview of ecological status, vulnerability and future perspectives of European large shallow, semi-enclosed coastal systems, lagoons and transitional waters. Estuar. Coast. Shelf Sci. 140 (1), 95-122.

O'Neill, K., Schreider, M., McArthur, L., Schreider, S., 2015. Changes in the water quality characteristics during a macroalgal bloom in a coastal lagoon. Ocean Coast. Manag. 118, 32-36.

Ostrom, E., 2009. A general framework for analyzing sustainability of social-ecological systems. Science 325, 419-422.

Pérez-Ruzafa, A., Marcos, C., Ros, J.D., 1991. Environmental and biological changes related to recent human activities in the Mar Menor (SE of Spain). Mar. Pollut. Bull. 23, $747-751$.

Pérez-Ruzafa, A., Navarro, S., Barba, A., Marcos, C., Cámara, M.A., Salas, F., 2000. Presence of pesticides through trophic compartments of the food web in the Mar Menor lagoon (SE Spain). Mar. Pollut. Bull. 40, 140-151.

Pérez-Ruzafa, A., Fernández, A.I., Marcos, C., Gilabert, J., Quispe, J.I., García-Charton, J.A., 2005. Spatial and temporal variations of hydrological conditions, nutrients and chlorophyll a in a Mediterranean coastal lagoon (Mar Menor, Spain). Hydrobiologia 550, 11-27.

Pérez-Ruzafa, A., Marcos, C., Pérez-Ruzafa, I.M., Pérez-Marcos, M., 2011. Coastal lagoons: "transitional ecosystems" between transitional and coastal waters. J. Coast. Conserv. 15 (3), 369-392.

Povilanskas, P., Razinkovas-Baziukas, A., Jurkus, E., 2014. Integrated environmental management of transboundary transitional waters: curonian Lagoon case study. Ocean Coast. Manag. 101, 14-23.

Robledano, F., Esteve, M.A., Martínez-Fernández, J., Farinós, P., 2011. Determinants of wintering waterbird changes in a Mediterranean coastal lagoon affected by eutrophication. Ecol. Indic. 11, 395-406.

Rodríguez-Gallego, L., Achkar, M., Defeo, O., Vidal, L., Meerhoff, E., Conde, D., 2017. Effects of land use changes on eutrophication indicators in five coastal lagoons of the Southwestern Atlantic Ocean. Estuar. Coast. Shelf Sci. 188, 116-126.

Subirats, J., Knoepfel, P., Larrue, C., Varone, F., 2012. Analysis and Public Policy Management. pp. 285 Barcelona, Ed. Ariel.

Sujitha, S.B., Jonathan, M.P., Escobedo-Urías, D.C., Aguirre-Bahena, F., Campos, E., Muñoz-Sevilla, N.P., 2017. Spatial variability of inorganic nutrients and physical parameters in the waters of Bahia Magdalena lagoon, Pacific Coast, Mexico. Acta Ecol. Sin. 37, 187-194.

Tavares, D.C., Guadagnin, D.L., de Moura, J.F., Siciliano, S., Merico, A., 2015. Environmental and anthropogenic factors structuring waterbird habitats of tropical coastal lagoons: implications for management. Biol. Conserv. 186, 12-21.

Thorne, K., Elliott-Fisk, D., Freeman, Ch., Bui, T.V., Powelson, K., Janousek, C., Buffington, K., Takekawa, J., 2017. Are coastal managers ready for climate change? A case study from estuaries along the Pacific coast of the United States. Ocean Coast. Manag. 143, 38-50.

Tuan, T.H., My, N., Anh, L., Van Toan, N., 2014. Using contingent valuation method to estimate the WTP for mangrove restoration under the context of climate change: a case study of Thi Nai lagoon, Quy Nhon city, Vietnam. Ocean Coast. Manag. 95, 198-212.

Turner, K., Daily, G.C., 2008. The ecosystem services framework and natural capital conservation. Environ. Resour. Econ. 39, 25-35.

United Nations, 2012. GEO-5, Global Environment Outlook. Environment for the Future We Want. UNEP 528 pp.

Velasco, J., Lloret, J., Millan, A., Marin, A., Barahona, J., Abellan, P., Sanchez-Fernandez, D., 2006. Nutrient and particulate inputs into the Mar Menor lagoon (SE Spain) from an intensive agricultural watershed. Water, Air, Soil Pollut. 176, 37-56.

Yáñez-Arancibia, A., Day, J., Sánchez-Gil, P., Day, J., Lane, R., Zárate-Lomelí, D. Vásquez, H., Rojas-Galaviz, J.L., Ramírez-Gordillo, J., 2014. Ecosystem functioning: the basis for restoration and management of a tropical coastal lagoon, Pacific coast of Mexico. Ecol. Eng. 65, 88-100.

Zaldívar-Jiménez, A., Ladrón de Guevara-Porras, P., Pérez-Ceballos, P., Díaz-Mondragón, S., Rosado-Solórzano, R., 2017. US-Mexico joint Gulf of Mexico large marine ecosystem based assessment and management: experience in community involvement and mangrove wetland restoration in Términos lagoon, Mexico. Environ. Dev. 22, 206-213. 